\title{
Ocular Findings Among Patients With Vitamin D Deficiency
}

Hatice Daldal $^{1}$, Ayla Gokmen Salici ${ }^{2}$

1. Department of Ophthalmology, Usak University Faculty of Medicine, Usak, TUR 2. Department of Internal Medicine, Usak University Training and Research Hospital, Usak, TUR

Corresponding author: Hatice Daldal, drhdaldal@hotmail.com

\section{Abstract \\ Objective}

The aim of this study was to evaluate the ocular findings in patients with low vitamin D levels.

\section{Methods}

All patients who attended the Internal Medicine Clinic between March 2018 and February 2020 with vitamin low D levels but had been untreated for the same were included in our study. The exclusion criteria were as follows: history of intraocular surgery, trauma, steroid use, secondary glaucoma, and history of rheumatologic diseases. The patients were classified into three groups: group 1 had severe deficiency with vitamin D levels below $10 \mu \mathrm{g} / \mathrm{L}$; group 2 had vitamin deficiency with levels of 10-20 $\mu \mathrm{g} / \mathrm{L}$; and group 3 had vitamin D insufficiency with levels of 20-30 $\mu \mathrm{g} / \mathrm{L}$. A comparison among groups was performed in terms of intraocular pressure (IOP), retinal nerve fiber layer (RNFL) thickness, central macular thickness (CMT), dry eyes, cataract, glaucoma, macular degeneration, and refractive error. The evaluation of statistical data was performed with the SPSS Statistics software version 22 (IBM, Armonk, NY).

\section{Results}

There were a total of 98 patients and 196 eyes, who were classified into three groups. There were 41 patients in group 1, 45 in group 2, and 12 in group 3. Groups were similar in terms of age $(\mathrm{p}=0.25)$ and gender $(\mathrm{p}=0.46)$. The average age among the cohort was $51 \pm 13.08$ years; 65 (66.3\%) of the patients were female and $33(33.7 \%)$ were male. There was no statistically significant difference in terms of IOP $(p=0.55)$, dry eyes $(\mathrm{p}=0.35)$, cataract $(\mathrm{p}=0.22)$, glaucoma $(\mathrm{p}=0.50)$, macular degeneration $(\mathrm{p}=0.64)$, and refractive error $(\mathrm{p}=0.46)$ among the groups. There was a statistically significant difference in CMT between group 1 and other groups ( $\mathrm{p}=0.002$ and $\mathrm{p}=0.002$, respectively). Also, there was a statistically significant difference in RNFL thickness between group 1 and group $2(\mathrm{p}=0.01)$. When compared in terms of quadrants, a significant difference was found only with regard to the nasal quadrant.

\section{Conclusion}

Review began 04/28/2021 Review ended 05/14/2021 Published 05/21/2021

\section{() Copyright 2021}

Daldal et al. This is an open access article distributed under the terms of the Creative Commons Attribution License CC-BY 4.0., which permits unrestricted use, distribution, and reproduction in any medium, provided the original author and source are credited.
Based on our findings, lower levels of 25-hydroxyvitamin D might be related to thinning in CMT. Regarding RNFL thickness, while there was a significant difference between groups 1 and 2, there was no difference between groups 1 and 3, and hence the association between lower levels of 25-hydroxyvitamin D and thinning in RNFL thickness could not be clearly established. Hence, we have assumed that lower levels of 25-hydroxyvitamin D might cause thinning in the macula and nasal quadrant of RNFL, and vitamin D deficiency might affect the nasal quadrant of RNFL primarily. Further long-term studies with a larger number of patients might clarify the relationship between vitamin D deficiency and the thinning in CMT, RNFL quadrants, and RNFL thickness.

Categories: Endocrinology/Diabetes/Metabolism, Internal Medicine, Ophthalmology

Keywords: vitamin d deficiency, ocular findings, retinal nerve fiber layer thickness, nasal quadrant, central macular thickness

\section{Introduction}

More than half of the global population is thought to be at risk of vitamin D deficiency [1]. Vitamin D deficiency is also widespread in Turkey. A meta-analysis has revealed a high rate of vitamin D deficiency in Turkey, which varies from 58.9-66.6\% [2,3]. Vitamin D deficiency can result in conditions such as rickets and osteomalacia $[4,5]$. Recently, vitamin D deficiency has been associated with many diseases such as cardiovascular disorders, metabolic syndrome, infectious and autoimmune conditions, as well as ocular diseases $[6,7,8]$. As per the classification based on 25-hydroxyvitamin D levels, individuals with levels over $30 \mathrm{ng} / \mathrm{ml}$ are considered to have sufficient vitamin D; however, levels of 20-30 ng/ml are classified as vitamin D insufficiency, levels below $20 \mathrm{ng} / \mathrm{ml}$ as deficiency of vitamin $\mathrm{D}$, and those below $10 \mathrm{ng} / \mathrm{ml}$ are regarded as serious deficiency of vitamin D [9]. In this study, we aimed to evaluate ocular findings among patients with 


\section{Materials And Methods}

This was a prospective study involving untreated patients with low levels of 25-hydroxyvitamin D who attended the Internal Medicine Clinic between March 2018 and February 2020. Ethical approval from the Usak University Faculty of Medicine Ethics Committee was obtained before commencing the study. Patients with a history of previous intraocular surgery, trauma, steroid use, secondary glaucoma, rheumatological disease, and other systemic additional diseases such as diabetes mellitus and hypertension were excluded from the study. Most of the patients had been referred with complaints of malaise and fatigue, while some patients had myalgia, and some patients were asymptomatic volunteers.

The patients were divided into three groups. Group 1 consisted of patients with severe 25-hydroxyvitamin D deficiency (below $10 \mu \mathrm{g} / \mathrm{L}$ ); group 2 comprised patients with 25-hydroxyvitamin D deficiency with levels between 10-20 $\mu \mathrm{g} / \mathrm{L}$; and group 3 consisted of patients with insufficiency of 25-hydroxyvitamin D with levels between $20-30 \mu \mathrm{g} / \mathrm{L}[9]$.

A comparative analysis was performed between the groups in terms of intraocular pressure (IOP), retinal nerve fiber layer (RNFL) thickness, central macular thickness (CMT), dry eyes, cataract, glaucoma, macular degeneration, and refractive error.

IOP was measured with an applanation tonometer. RNFL thickness and CMT values were measured using spectral-domain optical coherence tomography (OCT) (Cirrus HD-OCT 4000; Carl Zeiss Meditec, Jena, Germany). OCT measurements were done bilaterally. Perimetry was applied to patients who had a decrease in RNFL thickness and increase in cup/disc ratio and IOP for the diagnosis of glaucoma, in addition to routine ocular examination and evaluation of cup/disc ratio. The presence of dry eyes was evaluated by the Schirmer test and tear film break-up time test.

Statistical analysis was performed with the SPSS Statistics software version 22 (IBM, Armonk, NY), by using chi-square and Kruskal-Wallis tests. A p-value of $<0.05$ was considered to be statistically significant.

\section{Results}

The study involved 196 eyes of 98 patients: 41 in group 1, 45 in group 2, and 12 in group 3 . The groups were similar in terms of age $(\mathrm{p}=0.25)$ and gender $(\mathrm{p}=0.46) ; 65(66.3 \%)$ of the patients were female and $33(33.7 \%)$ were male. The average age was $49.17 \pm 13.00$ years in group $1,50.93 \pm 12.35$ years in group 2 , and $53.16 \pm$ 12.44 years in group 3 . There was no statistically significant difference between the groups in terms of IOP $(p=0.55)$, presence of dry eyes $(p=0.35)$, cataract $(p=0.22)$, glaucoma $(p=0.50)$, macular degeneration $(p=0.64)$, and refractive error $(\mathrm{p}=0.46)$ (Table 1$)$.

However, there was a statistically significant difference in CMT between group 1 and other groups (243 \pm $18.4 \mu, 252 \pm 17 \mu, 256 \pm 13.4 \mu ; \mathrm{p}=0.002, \mathrm{p}=0.002$, respectively). There was no statistically significant difference in CMT between group 2 and group $3(252 \pm 17 \mu, 256 \pm 13.4 \mu ; \mathrm{p}=0.30)$. There was a statistically significant difference in RNFL thickness between group 1 and group $2(93.7 \pm 9.89 \mu, 91.4 \pm 8.51 \mu ; p=0.01)$. When group 1 and group 3, and group 2 and group 3 were compared, there was no statistically significant difference in RNFL thickness $(93.7 \pm 9.89 \mu, 91.4 \pm 8.51 \mu, 94.8 \pm 7.47 \mu ; \mathrm{p}>0,99, \mathrm{p}=0.26$, respectively) (Table 2).

When compared in terms of quadrants, there was a significant difference only with regard to the nasal quadrant: a significant difference was observed between groups 2 and 3 (mean nasal quadrant of RNFL was $68.53 \mu$ in group $1,67.72 \mu$ in group 2 , and $74.95 \mu$ in group 3) (Table 3). 


\section{Cureus}

\begin{tabular}{|c|c|c|c|c|}
\hline Variables & Group $1(n=41)$ & Group $2(n=45)$ & Group $3(n=12)$ & $\begin{array}{l}P \text { - } \\
\text { value }\end{array}$ \\
\hline $\begin{array}{l}\text { IOP, } \mathrm{mmHg} \\
\text { (median } \pm \mathrm{SD} \text { ) }\end{array}$ & $13.30 \pm 2.91$ & $13.06 \pm 2.50$ & $12.45 \pm 2.08$ & 0,55 \\
\hline Dry eye, n (\%) & 14 (34.14\%) & 16 (35.55\%) & 4 (33.33\%) & 0.35 \\
\hline Cataract, n (\%) & $14(34.14 \%)$ & $15(33.33 \%)$ & $4(33.33 \%)$ & 0.22 \\
\hline $\begin{array}{l}\text { Glaucoma, n } \\
\text { (\%) }\end{array}$ & $0(0 \%)$ & $0(0 \%)$ & $0(0 \%)$ & 0.50 \\
\hline $\begin{array}{l}\text { Macular } \\
\text { degeneration, n } \\
\text { (\%) }\end{array}$ & $4(9.75 \%)$ & $5(11.11 \%)$ & $1(8.33 \%)$ & 0.64 \\
\hline $\begin{array}{l}\text { Refractive } \\
\text { error, } \mathrm{n}(\%)\end{array}$ & $\begin{array}{l}\text { Myopia: } 9 \text { (21.95\%); hyperopia: } 7 \\
\text { (17.07\%); astigmatism: } 14 \text { (34.14\%) }\end{array}$ & $\begin{array}{l}\text { Myopia: } 10 \text { (22.22\%); hyperopia: } 7 \\
\text { (15.55\%); astigmatism: } 16(35.55 \%)\end{array}$ & $\begin{array}{l}\text { Myopia: } 3 \text { (25\%); hyperopia: } 2 \\
\text { (16.66\%); astigmatism: } 4 \text { (33.33\%) }\end{array}$ & 0.46 \\
\hline
\end{tabular}

TABLE 1: Comparison between groups in terms of IOP, presence of dry eyes, cataract, glaucoma, macular degeneration, and refractive error

SD: standard deviation; IOP: intraocular pressure

\begin{tabular}{|c|c|c|c|c|}
\hline Variables & $\begin{array}{l}\text { Group } 1 \\
(n=41)\end{array}$ & $\begin{array}{l}\text { Group } 2 \\
(n=45)\end{array}$ & $\begin{array}{l}\text { Group } 3 \\
(n=12)\end{array}$ & $\begin{array}{l}\text { P-value (group1 vs. group 2/group } 2 \text { vs. group 3/group } 1 \text { vs. } \\
\text { group 3) }\end{array}$ \\
\hline CMT, $\mu$ (mean \pm SD) & $243 \pm 18.4$ & $252 \pm 17$ & $256 \pm 13.4$ & $0.002^{*} / 0.30 / 0.002^{*}$ \\
\hline $\begin{array}{l}\text { RNFL thickness, } \mu \text { (mean } \pm \\
\text { SD) }\end{array}$ & $93.7 \pm 9.89$ & $91.4 \pm 8.51$ & $94.8 \pm 7.47$ & $0.01 * / 0.06 / 0.86$ \\
\hline
\end{tabular}

TABLE 2: Comparison between groups in terms of CMT and RNFL thickness

*Statistically significant

SD: standard deviation; CMT: central macular thickness; RNFL: retinal nerve fiber layer

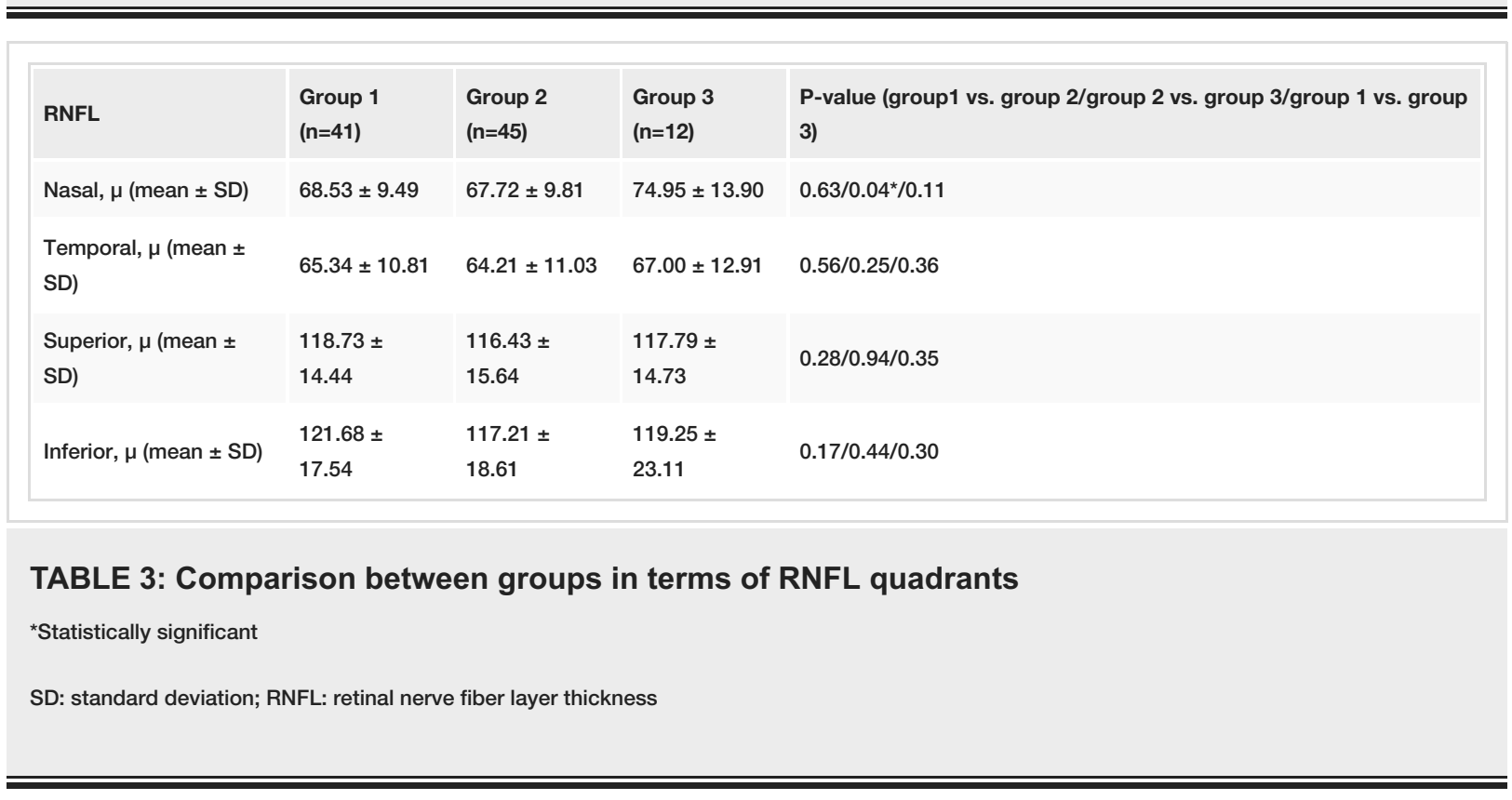




\section{Discussion}

Recent studies have revealed that vitamin D deficiency can lead to various ocular diseases. Those with low 25-hydroxyvitamin D levels have been associated with the risk of diseases involving dry eyes, diabetic retinopathy, myopia, age-related macular degeneration (AMD), whereas higher levels have been linked with decreased frequency of diseases. Also, vitamin $\mathrm{D}$ treatment has been experimentally shown to improve the conditions of those with diseases such as retinoblastoma, choroidal melanoma, retinal aging, ischemic retinopathy, diabetic retinopathy, autoimmune uveitis, corneal damage, and glaucoma [8].

There are studies that show that vitamin D affects eye cells. Initially, vitamin D-dependent calcium-binding protein was found in the human retina [10]. Afterward, vitamin D receptors (VDR) were detected in the cornea, lens, epithelia of the ciliary body, retinal pigment epithelia, corneal endothelium, ganglion cell layer, and photoreceptors with immunohistochemical staining [11]. VDRs are expressed in the retina and choroid by vascular endothelial cells [12]. Recently, vitamin D hydroxylase has been detected in the corneal epithelium, endothelium, sclera, non-pigmented ciliary epithelium, and retinal pigment epithelium, and these cells have been thought to play a part in vitamin D metabolism [13].

In a study by Tideman et al., consisting of a total of 2,666 children aged six years onwards, low 25hydroxyvitamin D concentration in serum was found to be related to longer axial length and higher risk of myopia, regardless of the level of outdoor exposure [14]. In another study by Mutti, it was speculated that 25-hydroxyvitamin D might have a potential therapeutic effect in controlling the increase in myopia rates [15]. In a study by Yazar et al., 221 (23.4\%) of 946 participants were found to have myopia. Individuals with myopia have been shown to have lower serum 25-hydroxyvitamin D concentrations compared to nonmyopic participants. Low serum 25-hydroxyvitamin D levels have been associated with a higher risk of myopia ( $<50 \mathrm{vs.} \geqslant 50 \mathrm{nmol} / \mathrm{L} ; \mathrm{p}<0.001$ ). The prevalence of myopia has been reported to be significantly higher in vitamin D-deficient individuals compared with patients who have sufficient amounts of vitamin D [16].

In a study by Choi et al., a total of 2,038 individuals aged 13-18 years were evaluated, and low 25hydroxyvitamin D levels were found to be associated with the prevalence of myopia. This relationship has been reported to be more remarkable in adolescents with high myopia [17]. Some studies have indicated variations in the VDR as a potential risk factor for myopia development. The VDR gene is located near the loci found to be related to myopia (MYP-3). These results suggest that the VDR gene does not play a direct role in myopia development, but it can indirectly contribute to the risk caused by mechanical stress factors or growth factors, by way of its role in calcium homeostasis and the regulation of ciliary muscle function [18].

In our study, there was no significant difference between the groups in terms of myopia or other refraction errors. The reason for this is that all the patients included in the study had a 25 -hydroxyvitamin D level below $30 \mu \mathrm{g} / \mathrm{L}$, and there were no patients with levels above $30 \mathrm{ng} / \mathrm{ml}$.

There are studies in the literature on AMD, which is one of the diseases linked with the deficiency of vitamin D. In a study consisting of a total of 96 patients, including 30 with late-stage AMD, 32 with early-stage AMD, and 34 normal controls, it was hypothesized that the deficiency of vitamin D might increase the risk of early and late AMD and might be related to subretinal fibrosis [19].

A diet rich in vitamin $\mathrm{D}$ has been shown to prevent or delay the progression to advanced AMD, particularly neovascularization [20]. High vitamin D levels are associated with a decreased risk of early or advanced stages of AMD in many studies. In a study by the Carotenoids in Age-related Eye Disease Study (CAREDS) group consisting of 1,313 people, the risk of early-stage AMD was found to be $48 \%$ less in women under 75 years of age with 25 -hydroxyvitamin D levels above $30 \mathrm{ng} / \mathrm{ml}$. This study suggests that 25 -hydroxyvitamin D may have a preventive effect in early-stage AMD in those under 75 years of age [21].

In another study involving 7,752 people over 40 years of age, patients with 25 -hydroxyvitamin D levels above $34 \mathrm{ng} / \mathrm{ml}$ and those with levels below $17 \mathrm{ng} / \mathrm{ml}$ were compared, and it was found that the risk of earlystage AMD was $36 \%$ and the risk of soft drusen was $24 \%$ less in individuals with 25 -hydroxyvitamin D levels above $34 \mathrm{ng} / \mathrm{ml}$ [22]. In a study by Graffe et al., age, gender, comorbidity, cognitive changes, body mass index, mean arterial pressure, visual acuity, IOP, and serum Ca levels were evaluated as possible contradictory factors when the test was performed and corrected. Macular thickness was reported to be thinner in the group with low 25-hydroxyvitamin D levels compared to those with sufficient levels (232.9 \pm $40.4 \mu$ and $253.3 \pm 32.1 \mu$, respectively) [23]. Similarly, in our study, a significant difference was detected between group 1 and other groups in terms of CMT $(243 \pm 18.4 \mu, 252 \pm 17 \mu, 256 \pm 13.4 \mu)$. Hence, we hypothesize that lower levels of 25-hydroxyvitamin D might cause macular thinning.

In the study by Dikci et al. involving 31 pseudoexfoliation cases with glaucoma, 34 cases with pseudoexfoliation syndrome, and 43 controls, 25 -hydroxyvitamin D levels details of glaucoma surgery were compared between the groups. There was no significant difference between 25 -hydroxyvitamin D levels. Based on this finding, 25-hydroxyvitamin D level was thought to have no effect on the development of pseudoexfoliation glaucoma/syndrome [24]. In another study, deficiency of vitamin D and the presence of 
BsmI 'B' allele and TaqI 't' allele were found to be related risk factors in glaucoma development [25]. In our study, glaucoma was not detected in any of the patients.

Some studies have shown that the deficiency of vitamin D is associated with cataracts [26,27]. In our study, cataracts were detected in $34.14 \%$ of the patients in group 1, 33.33\% in group 2, and $33.33 \%$ in group 3, and no difference was found between the groups. In a study by Demirci et al., it was determined that the deficiency of vitamin $\mathrm{D}$ is related to tear hyperosmolarity and tear film dysfunction and might cause susceptibility to dry eyes [28]. In the study by Kizilgul et al., replacement therapy was shown to improve tear osmolarity in patients who have vitamin D deficiency [29]. In our study, dry eyes were detected in $34.14 \%$ of the patients in group 1,35.55\% in group 2, and $33.33 \%$ in group 3 , and no significant difference was detected between the groups.

In the study by Uro et al. involving older patients, one group comprising patients with vitamin D deficiency $(<25 \mathrm{nmol} / \mathrm{L})$ and those with sufficient levels $(>25 \mathrm{nmol} / \mathrm{L})$ were compared. It was determined that the deficiency of vitamin $D$ in older patients is associated with decreased mean ganglion cell complex thickness before the loss of RNFL; there was no difference in the mean RNFL thickness between these two groups [30].

In our study, vitamin D deficiency's effect on RNFL quadrants was evaluated differently from other studies, and a difference in the thickness of the RNFL nasal quadrant was detected between the vitamin D-deficient group and the vitamin D-insufficient group. Although CMT was thinner in group 1 when compared to other groups, RNFL was greater in group 1 compared to group 2 but similar to group 3 . Thus, we could not establish a reliable association between 25 -hydroxyvitamin D levels and RNFL thickness. Studies with a larger cohort of patients are required to better evaluate vitamin D deficiency's effect on RNFL quadrants.

The main limitation of our study was the absence of a control group. Unfortunately, during the study period, none of the volunteers and patients who attended the Internal Medicine Clinic had 25-hydroxyvitamin D levels $>30 \mathrm{ng} / \mathrm{mL}$. This could be attributed to the high rate of vitamin D deficiency in our country, as shown in the previously mentioned meta-analysis [3]. Another limitation is the small number of patients in group 3. In light of these limitations, we believe that further long-term studies with a larger number of patients are required to provide more clarity on the relationship between vitamin D and the thinning in CMT, RNFL quadrants, and RNFL thickness.

This article was previously presented as an oral presentation at the Third International Hippocrates Congress on Medical and Health Sciences, on March 6-7, 2020 in Ankara, Turkey.

\section{Conclusions}

Based on our findings, the lower levels of 25-hydroxyvitamin D may be related to the thinning in CMT. In terms of RNFL thickness, while there was a significant difference between the severe vitamin d-deficient group (group 1) and the vitamin d-deficient group (group 2), there was no difference between the severe vitamin d-deficient group (group 1) and the vitamin d-insufficient group (group 3), and hence the association between lower levels of 25-hydroxyvitamin D and the thinning in RNFL thickness could not be conclusively established. When compared in terms of quadrants, there was a significant difference only with regard to the nasal quadrant between the vitamin D-deficient group (group 2) and the vitamin D-insufficient group (group 3). In light of these findings, we have hypothesized that lower levels of 25-hydroxyvitamin D might cause thinning in the macula and nasal quadrant of RNFL and vitamin D deficiency might affect the nasal quadrant of RNFL primarily.

\section{Additional Information \\ Disclosures}

Human subjects: Consent was obtained or waived by all participants in this study. Usak University Faculty of Medicine Ethics Committee issued approval 2018-010. This study was approved by the Usak University Faculty of Medicine Ethics Committee. Animal subjects: All authors have confirmed that this study did not involve animal subjects or tissue. Conflicts of interest: In compliance with the ICMJE uniform disclosure form, all authors declare the following: Payment/services info: All authors have declared that no financial support was received from any organization for the submitted work. Financial relationships: All authors have declared that they have no financial relationships at present or within the previous three years with any organizations that might have an interest in the submitted work. Other relationships: All authors have declared that there are no other relationships or activities that could appear to have influenced the submitted work.

\section{References}

1. Holick MF: Sunlight, UV-radiation, vitamin D and skin cancer: how much sunlight do we need? . Adv Exp Med Biol. 2008, 624:1-15. 10.1007/978-0-387-77574-6_1

2. Hekimsoy Z, Dinç G, Kafesçiler S, et al.: Vitamin D status among adults in the Aegean region of Turkey . BMC Public Health. 2010, 10:782. 10.1186/1471-2458-10-782

3. Alpdemir M, Alpdemir MF: Vitamin D deficiency status in Turkey: a meta-analysis . Int J Med Biochem. 2019, 
2:118-31. 10.14744/ijmb.2019.04127

4. Lips P, van Schoor NM: The effect of vitamin D on bone and osteoporosis . Best Pract Res Clin Endocrinol Metab. 2011, 25:585-91. 10.1016/j.beem.2011.05.002

5. Takahashi N, Udagawa N, Suda T: Vitamin D endocrine system and osteoclasts . Bonekey Rep. 2014, 3:495. 10.1038/bonekey.2013.229

6. Holick MF: Vitamin D: a D-Lightful health perspective. Nutr Rev. 2008, 66:S182-94. 10.1111/j.17534887.2008.00104.x

7. Hyppönen E, Boucher BJ, Berry DJ, Power C: 25-hydroxyvitamin D, IGF-1, and metabolic syndrome at 45 years of age: a cross-sectional study in the 1958 British Birth Cohort. Diabetes. 2008, 57:298-305. $10.2337 / \mathrm{db} 07-1122$

8. Reins RY, McDermott AM: Vitamin D: implications for ocular disease and therapeutic potential . Exp Eye Res. 2015, 134:101-10. 10.1016/j.exer.2015.02.019

9. Holick MF: Vitamin D deficiency. N Engl J Med. 2007, 357:266-81. 10.1056/NEJMra070553

10. Verstappen A, Parmentier M, Chirnoaga M, Lawson DE, Pasteels JL, Pochet R: Vitamin D-dependent calcium binding protein immunoreactivity in human retina. Ophthalmic Res. 1986, 18:209-14. 10.1159/000265436

11. Johnson JA, Grande JP, Roche PC, Campbell RJ, Kumar R: Immuno-localization of the calcitriol receptor, calbindin-D28k and the plasma membrane calcium pump in the human eye. Curr Eye Res. 1995, 14:101-8. 10.3109/02713689508999921

12. Choi D, Appukuttan B, Binek SJ, Planck SR, Stout JT, Rosenbaum JT, Smith JR: Prediction of cis-regulatory elements controlling genes differentially expressed by retinal and choroidal vascular endothelial cells. J Ocul Biol Dis Infor. 2008, 1:37-45. 10.1007/s12177-008-9007-1

13. Alsalem JA, Patel D, Susarla R, et al.: Characterization of vitamin D production by human ocular barrier cells. Invest Ophthalmol Vis Sci. 2014, 55:2140-7. 10.1167/iovs.13-13019

14. Tideman JW, Polling JR, Voortman T, et al.: Low serum vitamin D is associated with axial length and risk of myopia in young children. Eur J Epidemiol. 2016, 31:491-9. 10.1007/s10654-016-0128-8

15. Mutti DO: Vitamin D may reduce the prevalence of myopia in Korean adolescents . Invest Ophthalmol Vis Sci. 2014, 55:2048. 10.1167/iovs.14-14117

16. Hyppönen E, Boucher BJ, Berry DJ, Power C: 25-hydroxyvitamin D, IGF-1, and metabolic syndrome at 45 years of age: a cross-sectional study in the 1958 British Birth Cohort. Diabetes. 2008, 57:298-305. 10.2337/db07-1122

17. Choi JA, Han K, Park YM, La TY: Low serum 25-hydroxyvitamin D is associated with myopia in Korean adolescents. Invest Ophthalmol Vis Sci. 2014, 55:2041-7. 10.1167/IOVS.13-12853

18. Annamaneni S, Bindu CH, Reddy KP, Vishnupriya S: Association of vitamin D receptor gene start codon (Fok1) polymorphism with high myopia. Oman J Ophthalmol. 2011, 4:57-62. 10.4103/0974-620X.83654

19. Kim KL, Park SP: Association between serum vitamin D deficiency and age-related macular degeneration in Koreans: Clinical case-control pilot study. Medicine (Baltimore). 2018, 97:e11908. 10.1097/MD.0000000000011908

20. Merle BMJ, Silver RE, Rosner B, Seddon JM: Associations between vitamin D intake and progression to incident advanced age-related macular degeneration. Invest Ophthalmol Vis Sci. 2017, 58:4569-78. 10.1167/iovs.17-21673

21. Millen AE, Voland R, Sondel SA, et al.: Vitamin D status and early age-related macular degeneration in postmenopausal women. Arch Ophthalmol. 2011, 129:481-9. 10.1001/archophthalmol.2011.48

22. Parekh N, Chappell RJ, Millen AE, Albert DM, Mares JA: Association between vitamin D and age-related macular degeneration in the Third National Health and Nutrition Examination Survey, 1988 through 1994. Arch Ophthalmol. 2007, 125:661-9. 10.1001/archopht.125.5.661

23. Graffe A, Beauchet O, Fantino B, Milea D, Annweiler C: Vitamin D and macular thickness in the elderly: an optical coherence tomography study. Invest Ophthalmol Vis Sci. 2014, 55:5298-303. 10.1167/iovs.14-13918

24. Dikci S, Öztürk E, Fırat PG, Yılmaz T, Taşkapan MÇ, Yoloğlu S: The association of serum vitamin D levels with pseudoexfoliation glaucoma/syndrome. Endocr Metab Immune Disord Drug Targets. 2019, 19:166-70. 10.2174/1871530319666181128105911

25. Lv Y, Yao Q, Ma W, Liu H, Ji J, Li X: Associations of vitamin D deficiency and vitamin D receptor (Cdx-2, Fok I, Bsm I and Taq I) polymorphisms with the risk of primary open-angle glaucoma. BMC Ophthalmol. 2016, 16:116. 10.1186/s12886-016-0289-y

26. Brown CJ, Akaichi F: Vitamin D deficiency and posterior subcapsular cataract. Clin Ophthalmol. 2015, 9:1093-8. 10.2147/OPTH.S84790

27. Abdellah MM, Mohamed Mostafa E, Salama EH, Roshdy Mohamed E: Association of serum 25-hydroxyl vitamin D deficiency and age-related cataract: a case-control study. J Ophthalmol. 2019, 2019:9312929. $10.1155 / 2019 / 9312929$

28. Demirci G, Karaman Erdur S, Ozsutcu M, Eliacik M, Olmuscelik O, Aydin R, Kocabora MS: Dry eye assessment in patients with vitamin D deficiency. Eye Contact Lens. 2018, 44 Suppl 1:S62-5. 10.1097/ICL.0000000000000325

29. Kizilgul M, Kan S, Ozcelik O, Beysel S, Apaydin M, Ucan B, Cakal E: Vitamin D replacement improves tear osmolarity in patients with vitamin D deficiency. Semin Ophthalmol. 2018, 33:589-94. 10.1080/08820538.2017.1358752

30. Uro M, Beauchet O, Cherif M, Graffe A, Milea D, Annweiler C: Age-related vitamin D deficiency is associated with reduced macular ganglion cell complex: a cross-sectional high-definition optical coherence tomography study. PLoS One. 2015, 10:e0130879. 10.1371/journal.pone.0130879 